\title{
A retrospective study of demographic parameters and major health referrals among Afghan refugees in Iran
}

\author{
Salman Otoukesh ${ }^{1 *}$, Mona Mojtahedzadeh ${ }^{1}$, Dean Sherzai ${ }^{2}$, Arash Behazin ${ }^{3}$, Shahrzad Bazargan-Hejazi ${ }^{4}$
} and Mohsen Bazargan ${ }^{5}$

\begin{abstract}
Introduction: For nearly three decades, the two neighboring countries of Iran and Pakistan hosted millions of Afghans. Today, Afghans still represent the largest group of refugees in the world. This feature has greatly influenced provision of health care for this population. Due to a paucity of research on the health status of Afghan refugees in Iran, this study aim to make a vista on the pattern of different common diseases among Afghan refugees in Iran and use it as an index for performance evaluation of future health services to them.

Methods: This is a retrospective cross sectional study, in which we collected the demographic and medical data between 2005 and 2010 from referrals to the United Nations High Commissioner for Refugees (UNHCR) offices in Iran. We also considered a comparative review of the burden of disease estimates by the World Health Organization (WHO) for Afghanistan and Iran.

Results: Total numbers of referrals were 23,152 with $52.6 \%$ Female and $47.66 \%$ male. 29\% were $0-14$ years of age, $54 \%$ were $15-59$, and $17 \%$ were $60+$. The most common health referral for females and males (0-14) was perinatal diseases (15.16\%, 15.2\%, respectively). In the females (15-59) it was ophthalmic diseases (13.65\%), and for males it was nephropathies (21.4\%), and in both sexes (60+) age range it was ophthalmic diseases $(21.3 \%, 19.9 \%$, respectively). The largest ethnic group of afghan refugees in this study was Hazara (55\%) followed by Tajik (14\%), Fars (12\%), Sadat (9\%), and 10\% others. Ophthalmic diseases were the major cause of referrals by Hazara, Tajik, Fars, and Sadat groups with 26\%,20\%,26\%, and 27\% respectively. Referrals by pashtun group were mostly for neoplasms (17\%), among Uzbek group it was nephropathies (26\%), and in Baluch group Hematopoietic disorders (25\%).

Conclusion: These data indicate higher referral rate for women 15-59 years of old and people in 60+ with ophthalmic diseases, neoplasms, and nephropathies. Even given certain intrinsic limitations of such a study, we believe these unique findings are worth further explanation. This implies the need for public health researchers to pursue prospective studies in these areas.
\end{abstract}

Keywords: Refugee, Health status, Ethnicity

\footnotetext{
* Correspondence: salmanotoukesh@cdrewu.edu

${ }^{1}$ Department of Research, Charles R. Drew University of Medicine and

science, 1731 E. 120th street, Bldg. N, Los Angeles, CA 90059, USA

Full list of author information is available at the end of the article
} 


\section{Introduction}

Afghanistan's domestic upheaval in the 1970's, followed by the Soviet occupation in 1979, resulted in a massive displacement of its population. After the Soviet withdrawal in 1989 and the removal of the communist regime in 1992, about three million Afghans returned from exile. However, neither the rise of the Taliban in 1994, nor their fall in 2001, mitigated the challenges facing the diaspora who fled the country in different waves, and have had to maintain their immigrant status.

Years of conflict have inflicted near fatal wounds upon the healthcare infrastructure throughout Afghanistan. According to the Ministry of Public Health (2009), the country has suffered a devastating decline during the past three decades, with human and socio-economic indicators hovering near the bottom of international indices [1]. For nearly three decades, the neighboring countries of Iran and Pakistan have hosted millions of Afghans. Afghans today in fact represent the largest group of refugees in the world [2]. The Afghan situation in Iran is characterized by a) prolonged exile, b) large numbers (1,019,700 Afghan refugees as of July 2011), c) residence in urban areas, d) the emergence of a second generation, and e) a significant social support system provided by the host country [3-5]. These factors have largely shaped and determined healthcare for this population.

There is, however, a paucity of data on the health status of Afghans in exile. Previous studies were limited in scope in regards to sampling, or in areas of coverage. One clinic for Afghan refugees in Pakistan reported that most referrals were for gastrointestinal tract disorders, followed by respiratory tract complaints [6]. One research project in Northern Pakistan focused on the prevalence and etiology of visual loss and eye diseases in a resident Afghan refugee community [7]. A number of other studies have addressed tuberculosis (TB) and the mental health problems of Afghan refugees in Iran [8-15], Pakistan [16,17], the United States [18-21] and the Netherlands [22,23]. The scarcity of health data is also a challenge in Afghanistan. According to the Afghan Ministry of Public Health (2011), minimal data exists on the current health status of the population and on resource allocations in the health sector [24].

The World Health Organization (WHO) has stated that Afghanistan is a country where there is limited knowledge on most causes of mortality and morbidity [25]. Afghanistan's non-communicable diseases (NCD) country profile, as reported by WHO (2011), reveals that mortality estimates have a high degree of uncertainty because they are not based on any national NCD mortality data. These estimates are based on a combination of country life tables, cause of death models, regional cause of death patterns, and WHO and UNAID program estimates for some major causes of death. These do not include NCDs, which are estimated to account for $29 \%$ of all deaths in the WHO report [26]. Due to a paucity of research on the health status of Afghan refugees in Iran, this study aims to illustrate patterns of common diseases among Afghan refugees in Iran, and to use these data as an index for evaluating the performance of future health services.

\section{Methods}

This is a retrospective cross-sectional study that uses data collected from the UNHCR offices in Tehran and Mashhad. This database represents approximately $85 \%$ of Afghan refugees registered in Iran. These data were collected by two teams, each of which included at least three professional social workers and interviewers, one physician and one general purpose receptionist. These personnel, based in the UNHCR offices, held responsibility for extended areas in the central, northern and eastern parts of Iran.

Each case or patient approached UNHCR Offices for assistance, or were referred by hospitals, welfare, charity societies, or governmental and non-governmental organizations. Requests for assistance were screened and processed by the community and medical service teams through interviews conducted at home, in hospitals and in community visits. A report was recorded in the Community Integrated Social and Medical Assistance Program (CISAMAP) database by the interviewer after each case had given his or her consent. Records include all accepted and rejected cases for assistance, and are based on a list of referral causes (Additional file: 1) to ensure reliable data entry. Medical assessment of each case rested solely with the CISAMAP physician.

Data extracted for this study is based on a sample of 23,167 registered Afghan refugees who were referred from 2005 to 2010, a six year period. Tables and graphs represent disaggregated data for age, gender and ethnicity of Afghan refugees for inter- and intra-group comparisons. This information was reviewed along with the Global Burden of Disease 2011 Report released by WHO. SPSS (version 18) was used initially for data analysis; tables and graphs were prepared in Microsoft Word 2010.

\section{Findings}

The total number of cases in this study was 23,152. Most referrals were for females (52.6\%), followed by males (47.66\%) The most frequent causes for referrals were for ophthalmic diseases (23.7\%), neoplasm (13.3\%), nephropathies $(11 \%)$, ischemic heart diseases (10.4\%), and perinatal disorders (9.2\%) (Additional file: 1). The Hazara represented the largest ethnic group of Afghan refugees (40.47\%), followed by the Tajik (22\%), Pashtun (8.8\%), Sadat (6.6\%), Fars (5.25\%), Baluch (3.1\%), and Uzbek 
(2.51\%). By age, $38 \%$ of Afghan refugees in Iran are $0-14$, $59 \%$ are $15-59$, and $3 \%$ are $60+$ [27], with the percentage of referrals to UNHCR being 29\%, 54\%, and $17 \%$ for each of these groups, respectively. The highest referral rate was for females $60+$ years of age (17\%); for every 100 women age 60 and older, 17 received referrals. The rate for men in the same age group was 0.13 (Table 1 ).

\section{Cause of referrals for different age groups}

Prenatal disorders (30\%), ophthalmic diseases (21\%), and congenital anomalies (15\%) made up about $66 \%$ of referrals for patients 0-14 years of age. Ophthalmic diseases, nephropathies, neoplasm, and ischemic heart diseases were the most common cause of referrals for those 15-59 years of age (total $64 \%$ ), at $20 \%, 16 \%, 16 \%$, and $12 \%$ respectively. Ophthalmic diseases, ischemic heart disease, and neoplasm constituted $74 \%$ of referrals for those 60 or older, at $41 \%, 21 \%$, and $12 \%$ respectively Table 2 .

\section{Cause of referrals by gender}

In our study, 12,126 females (52.34\%) and 11,041 males (47.66\%) received referrals. Although more females received referrals than males, they shared the most common causes, including ophthalmic diseases (9.2\% vs. $14.4 \%)$, neoplasm (6.5\% vs. $6.8 \%$ ), nephropathies (6.4\% vs. $4.5 \%)$, and ischemic heart disease (5.2\% vs. $5 \%)$.

\section{Cause of referrals by ethnicity}

By ethnicity, the Hazara received the highest number of referrals (55\%), followed by the Tajik at $14 \%$, Fars at $11 \%$, Sadat at $8 \%$, Pashtun at $2 \%$, and Uzbek at $1 \%$. Ophthalmic diseases were the major cause of referrals with the Hazara, Tajik, Fars and Sadat at 26\%, 20\%, 26\%, and 27\% respectively. The disproportionate frequency of referrals among the Pashtun for neoplasmic disease (17\%) is noteworthy, as with nephropathies among the Uzbek at 26\%, and hematopoietic disorders (25\%) for the Baluch Table 3.

\section{Discussion}

The tremendous uncertainty that surrounds the health status of millions of refugees in exile underscores the need for health referral data for this population. Currently, the worldwide occurrence of non-communicable disease is $43 \%$, but is expected to increase to $60 \%$ and cause $73 \%$ of all deaths by 2020 . Most of this will occur through epidemics in developing countries such as Iran, especially among refugee populations [28-31].

\section{Age and gender}

Afghanistan is in the early stages of demographic transition, which will become more evident by 2025 [28,32]. The percentage of the population 65 years of age and older will increase from $2.1 \%$ in 2000 to $2.9 \%$ in 2025 [32]. Older residents are more likely to be affected by NCDs, and it is expected that disease rates will rise commensurate with aging [32].

The most common cause of referrals among 0-14 year olds was perinatal disorders, which are documented as communicable diseases in Afghanistan and Iran. In this age group, referral rates for males and females are identical. Better health status, along with greater access to health services in Iran, are thought to have resulted in reduced referral rate for refugees in this age group, compared to similar populations in Afghanistan. However, because medical costs are higher for refugees compared with citizens in Iran, limitations may eventually restrict access.

Those 15-59 years of age had 54\% of referrals and constitute the largest number of Afghan refugees. Ophthalmic diseases were the most common cause of referrals. Because this age group represents the bulk of the workforce in the diaspora, the impact of these diseases is clear. Referral rates in this group were higher for females. This can be attributed to the role of women as the head of the household, as well as to the documented reluctance of men to seek medical care due to the high cost [33].

In our study, only $17 \%$ of referrals were by refugees aged $60+$. The most common condition was ophthalmic, followed by cardiovascular disease. Referral rates were higher for women in this age group, which may be attributed to two factors. Afghan women in Iran have been traditionally involved in handicraft, which has been associated with greater occurrences of ophthalmic diseases [34,35]. In refugee settings, men are also seen to use health care services less frequently than women [33].

Chronic diseases such as heart disease and stroke are prevalent among elderly populations, including refugees

Table 1 Referral rates

\begin{tabular}{|c|c|c|c|c|c|c|c|c|c|c|}
\hline & \multicolumn{3}{|c|}{$0-14$} & \multicolumn{3}{|c|}{$15-59$} & \multicolumn{3}{|c|}{$60+$} & \multirow[t]{2}{*}{ Total } \\
\hline & Male & Female & All & Male & Female & All & Male & Female & All & \\
\hline Total in the country & 199397 & 186027 & 385424 & 329384 & 271050 & 600434 & 21748 & 13717 & 35465 & 1021323 \\
\hline Respective provinces & 150026 & 139967 & 289993 & 247829 & 203938 & 451767 & 16363 & 10321 & 26684 & 768444 \\
\hline Referrals & 3449 & 3261 & 6710 & 5503 & 7082 & 12585 & 2081 & 1776 & 3857 & 23152 \\
\hline Referral rates & 0.02 & 0.02 & 0.02 & 0.02 & 0.03 & 0.03 & 0.13 & 0.17 & 0.14 & 0.03 \\
\hline
\end{tabular}

Sources: Amayesh 2005 for total in the country and respective provinces (estimated) and UNHCR Database 2005-2010 for referral. 
Table 2 Causes of referrals by age and gender distribution

\begin{tabular}{|c|c|c|c|c|c|c|c|c|c|c|c|}
\hline \multirow[t]{2}{*}{ Cause of referrals } & & \multicolumn{3}{|c|}{ 0_14 } & \multicolumn{3}{|c|}{$15 \_59$} & \multicolumn{3}{|c|}{$60+$} & \multirow[t]{2}{*}{ Total } \\
\hline & & $\mathrm{F}$ & $M$ & All & $\mathbf{F}$ & $M$ & All & $\mathbf{F}$ & $M$ & All & \\
\hline \multirow[t]{2}{*}{ Ophtalmic disease } & Count & 80 & 580 & 1385 & 1591 & 790 & 2508 & 822 & 769 & 1591 & 5484 \\
\hline & $\%$ & $24.70 \%$ & $16.80 \%$ & $20.60 \%$ & $24.30 \%$ & $14.40 \%$ & $19.90 \%$ & $46.30 \%$ & $37.00 \%$ & $41.20 \%$ & $23.70 \%$ \\
\hline \multirow[t]{2}{*}{ Neoplasms } & Count & 267 & 327 & 594 & 1143 & 870 & 2013 & 164 & 312 & 476 & 3083 \\
\hline & $\%$ & $8.20 \%$ & $9.50 \%$ & $8.90 \%$ & $16.10 \%$ & $15.80 \%$ & $16.00 \%$ & $9.20 \%$ & 15.005 & $12.30 \%$ & $13.30 \%$ \\
\hline \multirow[t]{2}{*}{ Nephropathies } & Count & 105 & 128 & 233 & 859 & 1181 & 2040 & 87 & 188 & 275 & 2548 \\
\hline & $\%$ & 3.205 & $3.70 \%$ & 3.505 & $12.10 \%$ & $21.50 \%$ & $16.20 \%$ & $4.90 \%$ & $9.00 \%$ & $7.10 \%$ & $11.00 \%$ \\
\hline \multirow[t]{2}{*}{ Ischemic Heart Disease } & Count & 17 & 17 & 34 & 768 & 794 & 1562 & 389 & 412 & 801 & 2397 \\
\hline & $\%$ & $0.50 \%$ & $0.50 \%$ & $0.50 \%$ & $10.80 \%$ & $14.40 \%$ & $12.40 \%$ & $21.90 \%$ & $19.80 \%$ & $20.80 \%$ & $10.40 \%$ \\
\hline \multirow[t]{2}{*}{ Perinatal disease } & Count & 1017 & 1020 & 2037 & 57 & 36 & 93 & 2 & 0 & 2 & 2132 \\
\hline & $\%$ & $31.20 \%$ & $29.60 \%$ & $30.40 \%$ & $0.80 \%$ & $0.70 \%$ & $0.70 \%$ & $0.10 \%$ & $0.00 \%$ & $0.10 \%$ & $9.20 \%$ \\
\hline \multirow[t]{2}{*}{ Congenital anomalies } & Count & 485 & 531 & 1016 & 80 & 66 & 146 & 0 & 0 & 0 & 1162 \\
\hline & $\%$ & $14.90 \%$ & $15.40 \%$ & $15.10 \%$ & $1.10 \%$ & $1.20 \%$ & $1.20 \%$ & $0.00 \%$ & $0.00 \%$ & $0.00 \%$ & $5.00 \%$ \\
\hline \multirow[t]{2}{*}{ Appendicitis } & Count & 86 & 119 & 205 & 370 & 461 & 831 & 6 & 7 & 13 & 1049 \\
\hline & $\%$ & $2.60 \%$ & $3.50 \%$ & $3.10 \%$ & $5.20 \%$ & 8.40 & $6.60 \%$ & $0.30 \%$ & $0.30 \%$ & $0.30 \%$ & $4.50 \%$ \\
\hline \multirow[t]{2}{*}{ Labor complications } & Count & 4 & 2 & 6 & 754 & 5 & 759 & 1 & 0 & 1 & 766 \\
\hline & $\%$ & $0.10 \%$ & $0.10 \%$ & $0.10 \%$ & 10.60 & $0.10 \%$ & 6.00 & $0.10 \%$ & $0.00 \%$ & $0.00 \%$ & $3.30 \%$ \\
\hline \multirow[t]{2}{*}{ Deafness } & Count & 117 & 93 & 210 & 199 & 139 & 338 & 50 & 98 & 148 & 696 \\
\hline & $\%$ & $3.60 \%$ & $2.70 \%$ & $3.10 \%$ & $2.80 \%$ & $2.50 \%$ & $2.70 \%$ & 2.805 & $4.70 \%$ & $3.80 \%$ & $3.00 \%$ \\
\hline \multirow{2}{*}{$\begin{array}{l}\text { Liver, Billiary, Pancreas } \\
\text { disease }\end{array}$} & Count & 14 & 20 & 34 & 381 & 134 & 515 & 72 & 72 & 144 & 693 \\
\hline & $\%$ & $0.40 \%$ & $0.60 \%$ & $0.50 \%$ & $5.40 \%$ & $2.40 \%$ & $4.10 \%$ & $4.10 \%$ & $3.50 \%$ & $3.70 \%$ & $3.00 \%$ \\
\hline \multirow[t]{2}{*}{ Urinary disorders } & Count & 43 & 59 & 102 & 201 & 251 & 452 & 29 & 62 & 91 & 645 \\
\hline & $\%$ & $1.30 \%$ & $1.70 \%$ & $1.50 \%$ & $2.80 \%$ & $4.60 \%$ & $3.60 \%$ & $1.60 \%$ & $3.00 \%$ & $2.40 \%$ & $2.80 \%$ \\
\hline \multirow[t]{2}{*}{ Neurologic disorder } & Count & 144 & 190 & 334 & 81 & 144 & 225 & 37 & 40 & 77 & 636 \\
\hline & $\%$ & $4.40 \%$ & 5.505 & $5.00 \%$ & $1.10 \%$ & $2.60 \%$ & $1.80 \%$ & $2.10 \%$ & $1.90 \%$ & $2.00 \%$ & $2.70 \%$ \\
\hline \multirow[t]{2}{*}{ Fractures } & Count & 30 & 77 & 107 & 91 & 372 & 463 & 25 & 37 & 62 & 632 \\
\hline & $\%$ & $0.90 \%$ & $2.20 \%$ & $1.60 \%$ & $1.30 \%$ & $6.80 \%$ & $3.70 \%$ & $1.40 \%$ & $1.80 \%$ & $1.60 \%$ & 2.70 \\
\hline \multirow[t]{2}{*}{ Hematologic diseases } & Count & 96 & 265 & 361 & 117 & 137 & 254 & 3 & 6 & 9 & 624 \\
\hline & $\%$ & $2.90 \%$ & $7.70 \%$ & $5.40 \%$ & $1.70 \%$ & $2.50 \%$ & $2.00 \%$ & $0.20 \%$ & $0.30 \%$ & $0.20 \%$ & $2.70 \%$ \\
\hline \multirow[t]{2}{*}{ TB (all forms } & Count & 31 & 21 & 52 & 263 & 123 & 386 & 89 & 78 & 167 & 605 \\
\hline & $\%$ & $1.00 \%$ & 0.605 & $0.80 \%$ & $3.70 \%$ & $2.20 \%$ & $3.10 \%$ & $5.00 \%$ & $3.70 \%$ & $4.30 \%$ & $2.60 \%$ \\
\hline \multirow[t]{2}{*}{ Total } & $\%$ & 3261 & 3449 & 6710 & 7082 & 5503 & 12585 & 1776 & 2081 & 3857 & 23152 \\
\hline & & $100.00 \%$ & $100.00 \%$ & $100.00 \%$ & $100.00 \%$ & $100.00 \%$ & $100.00 \%$ & $100.00 \%$ & $100.00 \%$ & $100.00 \%$ & $100.00 \%$ \\
\hline
\end{tabular}

$[36,37]$. However, the reduced number of chronic cases in our population may be attributed to factors such as a) language barriers and incorrect interpretation and translation services [38], b) cultural and structural barriers [39], and c) the lack of access for preventative care and treatment [40].

\section{Ethnicity}

The Hazara, Tajik, Fars and Sadat ethnic groups incurred the most referrals for ophthalmic diseases, probably as a result of their trade and livelihood, e.g. construction workers, handicraft jobs $[34,35]$. The number of referrals for smaller groups such as the Pashtun and Baluch may not be truly representative, as they reside mainly in the south and southeast of Iran, and data for these populations may be incomplete.

Afghan refugees are uniquely distributed in neighboring countries for several reasons. With the communist takeover of 1978, their migration has been heterogeneous in regards to race and religion. History, culture and religious differences have had a significant impact on where Afghans have settled. Pashtuns have more often migrated to Pakistan because of ethnic, linguistic and religious similarities. Nearly 40 million Pakistanis in 
Table 3 Cause of referrals by ethnicity distribution

\begin{tabular}{|c|c|c|c|c|c|c|c|c|c|c|c|}
\hline Disease & & BALOCH & FARS & HAZARA & PASHTUN & SADAT & TAJIKA & UZBEK & OTHERS & NOT INDICATED & TOTAL \\
\hline \multirow[t]{2}{*}{ Ophtalmic disease } & Count & 7 & 682 & 3310 & 58 & 490 & 635 & 17 & 157 & 129 & 5485 \\
\hline & $\%$ & 9.2 & 26.2 & 25.9 & 10.2 & 27.3 & 19.6 & 12.4 & 11.8 & 21.3 & 23.7 \\
\hline \multirow[t]{2}{*}{ Neoplasma } & Count & 16 & 290 & 1646 & 99 & 172 & 493 & 17 & 242 & 109 & 3084 \\
\hline & $\%$ & 21.1 & 11.1 & 12.9 & 17.3 & 9.6 & 15.2 & 12.4 & 18.1 & 18 & 13.3 \\
\hline \multirow[t]{2}{*}{ Nephropathies } & Count & 6 & 158 & 1461 & 61 & 219 & 371 & 35 & 188 & 49 & 2548 \\
\hline & $\%$ & 1.9 & 6.1 & 11.4 & 10.7 & 12.2 & 11.4 & 25.5 & 14.1 & 8.1 & 11 \\
\hline \multirow[t]{2}{*}{ Ischemic Heart Disease } & Count & 5 & 437 & 1150 & 51 & 165 & 375 & 4 & 146 & 64 & 2397 \\
\hline & $\%$ & 6.6 & 16.8 & 9 & 8.9 & 9.2 & 11.6 & 2.9 & 10.9 & 10.5 & 10.3 \\
\hline \multirow[t]{2}{*}{ Perinatal disease } & Count & 1 & 203 & 1140 & 72 & 188 & 305 & 10 & 134 & 85 & 2138 \\
\hline & $\%$ & 1.3 & 7.8 & 8.9 & 12.6 & 10.5 & 9.4 & 7.3 & 10 & 14 & 9.2 \\
\hline \multirow[t]{2}{*}{ Congenital anomalies } & Count & 4 & 38 & 644 & 52 & 86 & 182 & 19 & 95 & 48 & 1168 \\
\hline & $\%$ & 5.3 & 1.5 & 5 & 9.1 & 4.8 & 5.6 & 13.9 & 7.1 & 7.9 & 5 \\
\hline \multirow[t]{2}{*}{ Appendicitis } & Count & 1 & 206 & 534 & 10 & 74 & 162 & 0 & 45 & 17 & 1049 \\
\hline & $\%$ & 1.3 & 7.94 & 4.2 & 1.8 & 4.1 & 5 & & 3.4 & 2.8 & 4.5 \\
\hline \multirow[t]{2}{*}{ Labor complications } & Count & 0 & 116 & 432 & 4 & 49 & 137 & 1 & 20 & 7 & 766 \\
\hline & $\%$ & & 4.5 & 3.4 & 0.7 & 2.7 & 4.2 & 0.7 & 1.5 & 1.2 & 3.3 \\
\hline \multirow[t]{2}{*}{ Deafness } & Count & 1 & 137 & 384 & 2 & 70 & 83 & 0 & 15 & 4 & 696 \\
\hline & $\%$ & 1.3 & 5.3 & 3 & 0.4 & 3.9 & 2.6 & & 1.1 & 0.7 & 3 \\
\hline \multirow[t]{2}{*}{ Liver, Billiary, Pancreas disease } & Count & 8 & 15 & 423 & 34 & 62 & 84 & 8 & 30 & 29 & 693 \\
\hline & $\%$ & 10.5 & 0.6 & 3.3 & 6 & 3.5 & 2.6 & 5.8 & 2.2 & 4.8 & 3 \\
\hline \multirow[t]{2}{*}{ Urinary disorders } & Count & 3 & 136 & 321 & 13 & 51 & 90 & 0 & 24 & 7 & 645 \\
\hline & $\%$ & 3.9 & 5.2 & 2.5 & 2.3 & 2.8 & 2.8 & & 1.8 & 1.2 & 2.8 \\
\hline \multirow[t]{2}{*}{ Neurologic disorder } & Count & 2 & 143 & 317 & 6 & 53 & 78 & 1 & 30 & 6 & 636 \\
\hline & $\%$ & 2.6 & 5.5 & 2.5 & 1.1 & 3 & 2.4 & 0.7 & 2.2 & 1 & 2.7 \\
\hline \multirow[t]{2}{*}{ Fracture } & Count & 3 & 18 & 399 & 20 & 43 & 81 & 14 & 37 & 17 & 632 \\
\hline & $\%$ & 3.9 & 0.7 & 3.1 & 3.5 & 2.4 & 2.5 & 10.2 & 2.8 & 2.8 & 2.7 \\
\hline \multirow[t]{2}{*}{ Hematologic diseases } & Count & 19 & 10 & 213 & 63 & 35 & 108 & 5 & 155 & 17 & 625 \\
\hline & $\%$ & 25 & 0.4 & 1. & 11 & 1.9 & 3.3 & 3.6 & 11.6 & 2.8 & 2.7 \\
\hline \multirow[t]{2}{*}{ TB (all forms } & Count & 0 & 15 & 426 & 26 & 39 & 57 & 6 & 17 & 19 & 605 \\
\hline & $\%$ & & 0.6 & 3.3 & 4.6 & 2.2 & 1.8 & 4.4 & 1.3 & 3.1 & 2.6 \\
\hline Total & $\%$ & $100 \%$ & $100 \%$ & $100 \%$ & $100 \%$ & $100 \%$ & $100 \%$ & $100 \%$ & $100 \%$ & $100 \%$ & $100 \%$ \\
\hline
\end{tabular}

Source: UNHCR Database 2005-2010.

the region bordering Afghanistan are of Pashtun origin, speak Pashtu and are Sunni Muslims, germane to their Afghan refugee counterparts. The Hazara are mostly Shiite, speak Farsi, and live mainly in the northern and northeastern regions of Afghanistan. This religious and linguistic proximity draws them disproportionately to Iran (55\% vs. $40.47 \%$ of all refugees) [41].

\section{Limitations}

The retrospective analysis of data from UNHCR offices in Iran limits our choice of variables, and may be inferior to a prospective, active data collection research paradigm. Most retrospective studies rely on the accuracy of data records, and/or the recollection of individuals.
Similarly, our study has relied on the accuracy of data entry by interviewers. Moreover, inconsistencies in record keeping between UNHCR offices did not allow comprehensive data to be compiled for the entire country of Iran. Referral rates were calculated assuming equal access to referrals by all Afghan refugees, and on the homogeneous distribution of age groups in the country.

There are more than 2 million unregistered foreigners in Iran, mostly Afghan and Iraqi nationals, who were not included in this study [3]. This report also does not consider communicable, diarrheal and parasitic diseases which are prevalent in Afghanistan and are considered a major part of the healthcare burden in Iran [42]. These conditions may be mitigated by access to safe drinking 
water and vaccination, and allocation of resources to costly in-patient treatment and care.

\section{Conclusions}

Our study is unique in that it provides a comprehensive look into perhaps the largest diaspora of Afghans. Important findings include that, for those 0-14 years of age, prenatal disease was the most common cause in seeking healthcare, whereas those $15-59$ and $>60$ years of age were referred primarily for ophthalmic diseases, neoplasms, and nephropathies. We also highlight differences in disease proclivity by ethnicity, which may facilitate better access and effective treatment. Despite the intrinsic limitations inherent in such a study, these findings promise to provide insight into providing improved access and care for this beleaguered population.

\section{Additional file}

Additional file 1: Appendix1. Cause of referrals.

\section{Competing interests}

The authors declare that they have no competing interests.

\section{Authors' contributions}

SO, MM, AB and D.SH were involved in the study from the design to the final manuscript. MM, MB and SH.B-H analyzed the data. AB drafted the first manuscript. SO, D.SH and MB reviewed the paper. All authors have read and approved the final manuscript.

\section{Acknowledgement}

We are immensely grateful to the CISAMAP team in AOR/Tehran (Sanaz Kahestan, Ladan Moshari, Shima Balout, Parisa Masjedi, Shima Heidari, and Yalda Saidi), without whose help and support this work would not have been possible.

Dr. M. Bazargan's research activity was partially supported by the Charles R. Drew University of Medicine and Science, AXIS program, Grant\#

U54MD007598 from the National Institute of Health-NIMHD.

\section{Author details}

${ }^{1}$ Department of Research, Charles R. Drew University of Medicine and science, 1731 E. 120th street, Bldg. N, Los Angeles, CA 90059, USA ${ }^{2}$ Department of Neurology, Loma Linda University, 11370 Anderson Street, Loma Linda, CA 92350, USA. ${ }^{3}$ UNHCR, Department of Field Unit, No 3, East Emdad St, Mollasadra Ave, Tehran 19917, Iran. ${ }^{4}$ Department of Medical Education Program, Charles R. Drew University of Medicine and science, 1731 E. 120th street, Los Angeles, CA 90059, USA. ${ }^{5}$ Department of Research, Charles R. Drew University of Medicine and science, 1731 E. 120th street, Bldg. N, Los Angeles, CA 90059, USA.

Received: 13 July 2012 Accepted: 10 December 2012

Published: 20 December 2012

\section{References}

1. http://moph.gov.af/content/media/Documents/HNSS-Report-ENG-v41281220101156987.pdf.

2. Schöch R, et al: Afghan refugees in Pakistan during the 1980s: Cold War politics and registration practice. The UN Refugee Agency, Policy Development and Evaluation Service. 2008. http://www.unhcr.org/4868daad2.pdf.

3. http://www.immi.gov.au/media/publications/pdf/2011/cgn-iran-july-2011.pdf.

4. UNHCR Annual Report: Public Health, Nutrition, HIV and WASH. 2010, http://www.unhcr.org/4e523e209.html.
5. Abbasi Shavazi MJ, Sadeghi R: The adaptation of second-generation Afghans in Iran. Middle East Institute - Fondation Recherche Strategique (MEI-FRC); 2011.

6. Morgan WA, et al: Experience of a clinic for Afghan refugees in Pakistan. West J Med 1988, 149(2):234-238.

7. Ihsan., H.R.A.a.T: Prevalence of visual impairment and eye diseases in Afghan refugees in Pakistan. East Mediterr Health J 1998, 4(3):560-566.

8. Azizi F, Rahimi AHK, Khosravizadegan F, Amiri M: Mental health problems prevalence and the associated effective demographic factors in Afghan refugees resettled in Dalakee refugee camp in 2005. Eur Psychiatry 2008, 23:269-270.

9. Farooq N, Mufti KA, Ayub M, Haroon A, Saifi F, Qureshi SM, Ihsan A, Chaudry HR, Dagarwal SR, Kingdon D: Psychiatric morbidity among Afghan refugees in Peshawar, Pakistan. J Ayub Med Coll 2005, 17(2):23-25.

10. Farnia $P$, et al: The recent-transmission of mycobacterium tuberculosis strains among Iranian and Afghan relapse cases: a DNA-fingerprinting using RFLP and spoligotyping. BMC Infect Dis 2008, 8:109.

11. Kalafi $Y$, Hagh-Shenas $H$, Ostovar A: Mental health among Afghan refugees settled in Shiraz, Iran. Psychol Rep 2002, 90:262-266.

12. Khazaei HA, Rezaei N, Bagheri GR, Dankoub MA, Shahryari KH, et al: Epidemiology of tuberculosis in the Southeastern Iran. European $\lrcorner$ Epidemiol 2005, 20(10):879-883.

13. Moradi M, Arababadi MK, Hassanshahi G: Tuberculosis in the Afghan immigrant in Kerman province of Iran. J Bio/ Sci 2008, 8(6):1107-1109.

14. Velayati AA, Farnia P, Mirsaeidi M, Masjedi RM: The most prevalent Mycobacterium tuberculosis super families among Iranian and Afghan TB cases. J Infect Dis 2006, 38(6-7):463-468.

15. Yazdanpanah M, Masjedi H, Hosseini M, Velayati AA, Masjedi M, Hakim R: Tuberculosis status among Iranian and Afghan patients referred to the national research institute of tuberculosis and lung disease during 1998-2000. Tanaffos J Respir Dis 2003, 5(4):241-246.

16. Kassam A, Nanji A: Mental health of Afghan refugees in Pakistan a qualitative rapid reconnaissance field study. Intervention 2006, 4(1):58-66.

17. Naeem F, et al: Psychiatric morbidity among Afghan refugees in Peshawar, Pakistan. J Ayub Med Coll Abbottabad 2005, 17(2):23-25.

18. Lipson JG: Afghan refugees in California: mental health issues. Issues in mental health nursing. 1993, 14(4):411-423.

19. Lipson JG, Hosseini T, Kabir S, Omidian PA, Edmonston F: Health Issues among Afghan women in California. Health Care Women Int 1995, 16(4):279-286

20. Omidian PA, Lipson JG: Health issues of afghan refugees in California, in cross-cultural medicine-a decade later [special issue]. West J Med 1992 157:271-275.

21. Lipson JG, et al: Afghan refugee health: some findings and suggestions, Volume 3. 1st edition. San Francisco: Department of Mental Health, Community and Administrative Nursing at the University of California; 1991:349-369

22. Gerritsen AA, Bramsen I, Devillé W, Willigen LH, Van Hovens JE, Ploeg HM: Health care utilization among asylum seekers and refugees in the Netherlands: design of a study. Soc Psychiatry Psychiatr Epidemiol 2006, 41 (nr. 1):18-26.

23. Ghosh N, Mohit A, Murthy RS: Mental health promotion in post-conflict countries. JRSH 2004, 124(6):268-270.

24. Ahmed R, labal M, Salehi AS: Afghanistan National health Accounts: Building a Framework for Sustainable Financing in Afghanistan Health Sector. http://www.deloitte.com/assets/Dcom-Unitedstates/local\%20Assets/ Documents/Federal/us_fed_NHA\%20Afghanistan\%20iHEA_090811.pdf.

25. World Health Organization: Global Burden of Disease. http://www.who.int/ topics/global_burden_of_disease/eu.

26. World Health Organization, D.o.M.a.H.I: NCD country of Afghanistan profile. 2011.

27. UNHCR: Operational guidance on refugee protection and solutions in urban areas. http://www.unhcr.org/4ea9552f9.pdf.

28. www.who.int/entity/ncd surveillance/strategy/en/index.html.

29. Lopez AD, Mathers CD, Ezzati M, Jamison DT, Murray CJL: Global and regional burden of disease and risk factors, 2001: Systematic analysis of population health data. The Lancet 2006, 367(9524):1747-1757.

30. Abegunde DO, Mathers CD, Adam T, Ortegon M, Strong $K$ : The burden and costs of chronic diseases in low-income and middle-income countries. The Lancet 2007, 370(9603):1929-1938.

31. Boutayeb A, Boutayeb S: The burden of non communicable diseases in developing countries. Int J Equity Health 2005, 4(1):2.

32. Bank TW: NCDS policy brief- Afghanistan. Organization: World Health; 2011:1-4. 
33. Ashrafi A, Moghissi H: Afghan in Iran: asylum fatigue overshadows islamic brotherhood (the Era of mass migration). Global Dialogue-The Era of Mass Migration 2002.

34. Wang CY, Wang F, Wang HM, Chen RJ, Yu WL: Occupational health status of migrant female workers of artificial gem manufacturing cottages in Guangxi, China. Chin Med J 2011, 29(9):646-649.

35. Duan XR, et al: Prevalence and associations of cataract in a rural Chinese adult population: the Handan Eye Study. Graefes Arch Clin Exp Ophthalmol 2012, In press.

36. Hoffman C, Rice D, Sung HY: Persons with chronic conditions: their prevalence and costs. JAMA 1996, 2:1473-1479.

37. Marengoni A, Winblad B, Karp A, Fratiglioni L: Prevalence of chronic diseases and multimorbidity among the elderly population. Am J Public Health 2008, 98(7):1198-1200

38. Hirsch J, Marano F: Better patient care through video interpretation: A New Jersey hospital uses teleconferencing tools and interpreters to break down patient language and hearing barriers. Health Manag Technol 2007, 28(3):31-37.

39. Griswold K, Zayas LE, Kernan JB, Wagner CM: Cultural awareness through medical student and refugee patient encounters. I Immigr Minor Health 2007, 9(1):55-60.

40. Palinkas LA, Pickwell SM, Brandstein K, Clark TJ, Hill LL, Moser RJ, et al: The journey to wellness: Stages of refugee health promotion and disease prevention. J Immigr Health 2003, 5(1):19-28.

41. Adelkhah F, Olszewska Z: The Iranian Afghans. Iraninan Stud 2007, 40(2):137-165.

42. Rajabali A, Moin O, Ansari AS, Khanani MR, Ali SH: Communicable disease among displaced Afghans: refuge without shelter. Nature Rev Microbiol 2009, 7:609-614.

doi:10.1186/1475-9276-11-82

Cite this article as: Otoukesh et al.: A retrospective study of demographic parameters and major health referrals among Afghan refugees in Iran. International Journal for Equity in Health 2012 11:82.

\section{Submit your next manuscript to BioMed Central and take full advantage of:}

- Convenient online submission

- Thorough peer review

- No space constraints or color figure charges

- Immediate publication on acceptance

- Inclusion in PubMed, CAS, Scopus and Google Scholar

- Research which is freely available for redistribution 